\title{
Design of College Evaluation System Based on Artificial Intelligence and Deep Learning Technology
}

\author{
Jiang Yan*, Wang Peipei \\ College of Electronical and Information Engineering, Henan Polytechnic Institute, Nanyang, Henan, \\ China \\ *Corresponding Author.
}

\begin{abstract}
Artificial intelligence and deep learning technology are important technologies widely used in manufacturing industry. With the help of performance appraisal system to comprehensively evaluate the performance of teachers is a good measure. Therefore, it is very necessary to develop a performance appraisal system for university teachers by using artificial intelligence technology. This paper first demonstrates the feasibility of the development of performance appraisal system, and scientifically divides the user roles. According to the business requirements, the core business process of the system is established, and the system architecture and functional modules are designed. At the same time, this paper establishes the conceptual model and logical model of database. Finally, SSH framework and extjs framework are used to realize the functions of the system. In this paper, the reliability, stability and security of the system are tested to ensure that the system meets the functional and non functional requirements. The operation results show that the system has stable functions, simple operation and convenient maintenance, and basically meets the needs of users at different levels.
\end{abstract}

Keywords: Performance appraisal, core business process, architecture, artificial intelligence, manufacturing industry.

\section{Introduction}

With the improvement of human resource management in Colleges and universities, the performance appraisal of staff in Colleges and universities needs further standardization and informatization to make the performance appraisal more fair and transparent [1-2]. The traditional university personnel management software does not include the performance appraisal of university staff into the scope of management, and there is no perfect system for the appraisal index of university staff, resulting in a series of problems such as heavy workload, inaccurate data and opaque process of each year-end appraisal. Let each performance appraisal only become a form, can not form a benign competitive environment [3]. A comprehensive and objective evaluation of teaching staff is helpful to improve their work attitude and quality, which can directly improve the quality of education and academic level of the school. And the results of performance appraisal will directly affect the staff rating, professional title and bonus.

The current performance appraisal method is mainly in the form of electronic form to each college, the person in charge of the college in accordance with the requirements of the personnel department after the assessment score reported to the personnel department for summary [4-5]. Because there is no flexible system to support, all the assessment content and elements need to be formulated in advance, and can not be set up according to the characteristics of each college, assessment content and elements are too single. In order to change this situation, we need to develop a set of faculty performance appraisal system on the basis of the original personnel management software, which can flexibly configure the appraisal content and elements, and establish a perfect performance appraisal process system on the system, so as to achieve the effect of high efficiency, accuracy, fairness and transparency.

ISSN: 0010-8189 


\section{Introduction of related technologies}

This chapter will introduce some technologies used in the development of this system, such as Silverlight technology, SQLServer 2008, ADO. NET, WCF technology and so on. Through the application of these technologies, we can solve the actual business needs and improve the technical level of the system.

\subsection{Silverlight technology}

Microsoftsilveriight is a cross-browser and cross-client platform technology, which is a front-end application development solution developed by Microsoft, one of the main application development platforms of Microsoft's Rich intemetApplication strategy, a part of Microsoft's UX (user experience) strategy, and one of Microsoft's attempts to clearly divide the work of art designers and program developers and cooperate with each other to develop applications.

\subsection{SQL Server 2008}

SQL Server is a relational database management system, and database engine is the core service of SQL Serer system, which is responsible for data storage, processing and security management. And provides a more reliable platform for strengthening database mirroring. It enables companies to run their most mission-critical applications, while reducing the cost of managing data infrastructure and sending observations and information to all users [6-7].

\section{ADO. NET technology}

ADO. NET is a set of classes that expose data access services to. net programmers. ADO. NET provides a rich set of components for creating distributed data sharing applications. It provides access to relational data, XML and application data. At the same time, it supports various development requirements, including creating front-end database clients and middle-tier business objects used by applications, tools, languages or Intemet browsers.

\subsection{WCF technology}

WCF, short for Windows Communication Foundation, is a set of application development interfaces for data communication developed by Microsoft, and is a part of. . NET framework. Microsoft integrates the communication methods provided by almost. . NET Framework, and designs a unified program development model-WCF, which provides the most basic and flexible support for data communication.

\section{System requirement analysis}

\subsection{Business process analysis}

According to the evaluation mechanism of university staff, we design and develop a set of performance management system to help universities realize the informatization, openness and transparency of performance evaluation, promote the continuous improvement of staff, enhance themselves, and enhance the cohesion of the school.

At the same time, the school leaders can grasp the working state of the teaching staff macroscopically and optimize the teaching staff team. The examinees are the staff and the examiners are the middle-level and senior leaders of the college. The personnel department formulates the assessment plan and sets the assessment contents and elements. Set up the staff to participate in the assessment, and set the middle and high-level leaders to score. After the implementation of the assessment plan, the corresponding middle-level leaders of the teaching staff will be submitted to the senior leaders for scoring [8-10]. The college will report all the staff's post assessment results to the personnel department. After the statistics and approval of the personnel department, the results will be publicized. If teachers have any questions, they can give feedback to the personnel department. After receiving the feedback, if the result needs to be changed, it needs to be approved by the senior leadership. 


\subsection{System function requirement analysis}

According to the business process analysis of the system, the participants of the system include the person in charge of the personnel department, the person in charge of the college, the middle and high-level leaders and the teaching staff, and their brief descriptions are shown in Table 1.

Table 1 System participants and brief description

\begin{tabular}{|c|c|}
\hline Participant & Explain \\
\hline Head of personnel department & $\begin{array}{c}\text { The person in charge of the personnel department } \\
\text { establishes the assessment element database, formulates the } \\
\text { assessment plan and summarizes the assessment results. }\end{array}$ \\
\hline Director of the College & $\begin{array}{c}\text { Set up assessors for the Faculty of the college, and } \\
\text { summarize the college assessment results. }\end{array}$ \\
\hline Middle and high level leaders & The middle and high level leaders scored the teaching staff. \\
\hline Teaching staff & Check your own assessment results and appeal if you have \\
any objection.
\end{tabular}

3.3 System non functional requirement analysis

(1) System performance requirements

The system requires real-time response to data operation. As long as it is submitted and saved, it can query and browse information in the system. The system should be able to work at various performance levels, and be able to meet the efficiency requirements of the application. The system requires that when 300 users submit interactive applications at the same time, the time to submit various forms should not be more than 2 seconds, the CPU utilization rate should be less than $75 \%$, and the memory utilization rate should be less than $70 \%$.

(2) System security requirements

The data is stored on the relatively safe hardware device, and the necessary data backup and recovery tools are implemented, and the data backup strategy and mechanism are formulated. All the passwords used in the system must be encrypted and stored with irreversible encryption algorithm. The system provides cascading authorization management function. Hierarchical authorization mechanism is used in authorization management. The upper level can set the operation authority of the next level. Data should have no ambiguity, and the system should ensure the integrity and consistency of data through transactions.

\section{System design}

\subsection{System architecture design}

The system is based on B / S architecture, using a web server, a database server. The physical architecture of the system is shown in Figure 1. 

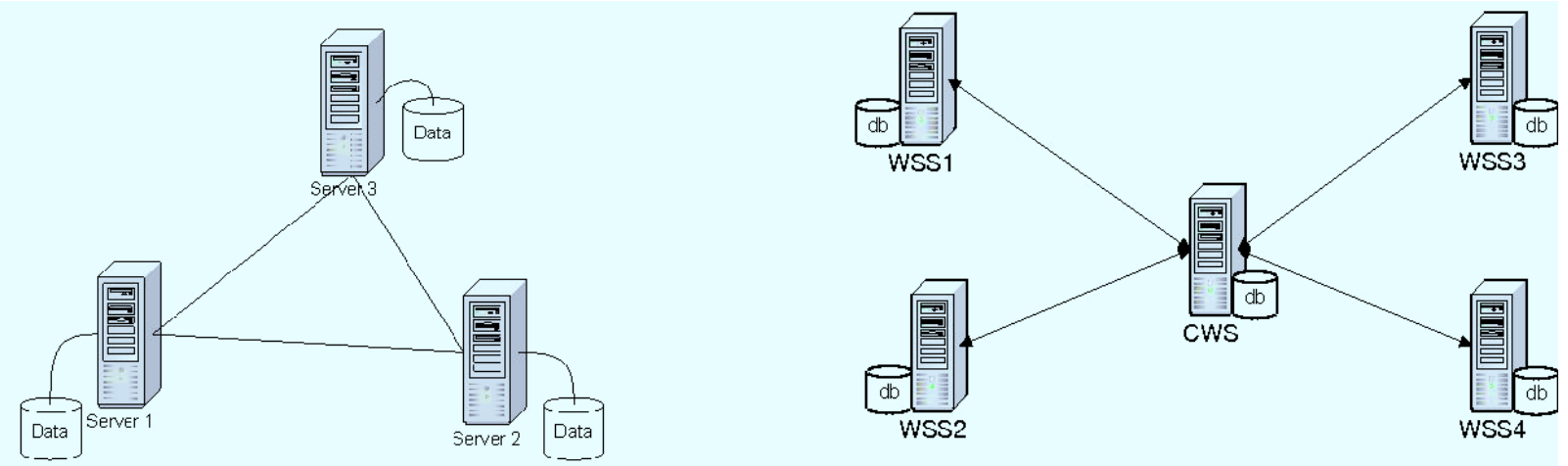

Fig 1:System physical architecture diagram

The software adopts MVC mode and builds the system based on. Net technology. The client uses Silverlight technology, the data access layer uses ado.net, and the WCF is used as the service layer. The software architecture of the system is shown in Figure 2.

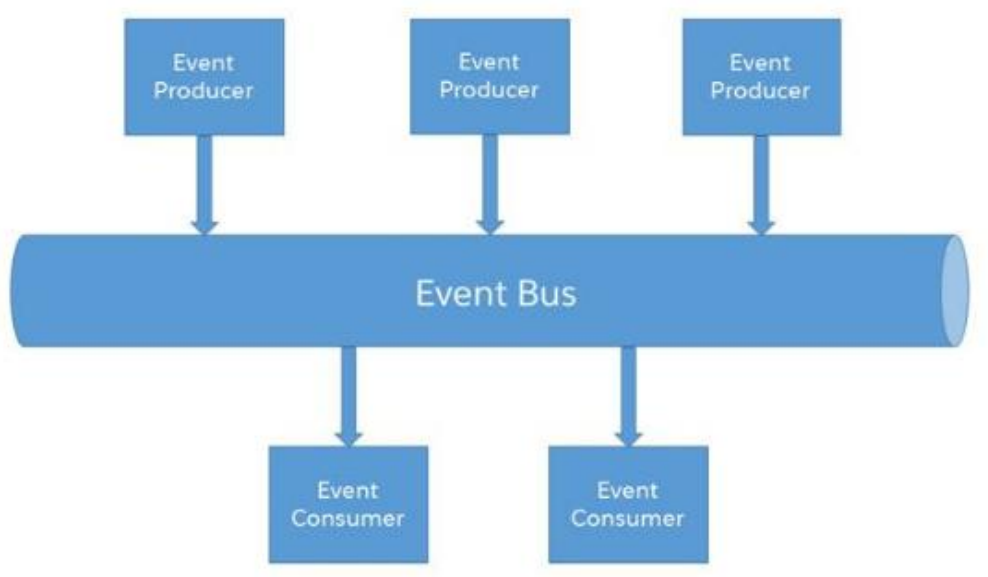

Fig 2:System software architecture diagram

\subsection{System function design}

According to the system analysis, the system has five modules: basic setting, assessment setting, assessment management, self-service platform and system management. The system structure is shown in Figure 3. The following is a detailed description of these modules.

ISSN: 0010-8189 


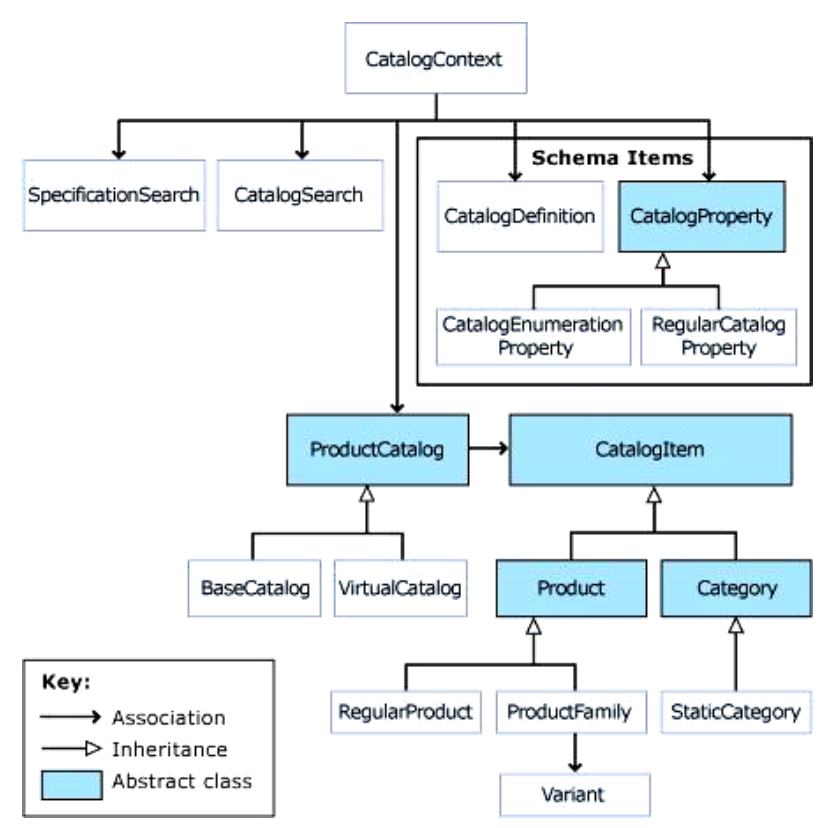

Fig 3:System function structure diagram

(1) Basic settings

The module of basic setting includes two sub modules: assessment content and assessment elements.

(2) Assessment settings

Assessment setting includes making assessment plan and setting assessment elements and staff for each assessment plan. The person in charge of the personnel department and the person in charge of the college can set assessors for the staff.

(3) Assessment management

After the assessment plan is determined, the assessment process needs to be monitored and managed, and the person in charge of the personnel department manages the whole cycle of the assessment plan.

(4) Self service platform

Teachers and staff can view their own assessment results on the self-service platform, and middle and high-level leaders can assess and score.

(5) System management

The system management has two modules of user management and authority management. The system administrator manages all the user information in the system. It needs user list interface and user form interface. The system administrator manages all kinds of roles in the system, and sets the corresponding function authority and data authority of these roles.

\section{System implementation}

\subsection{System implementation environment}

The system implementation environment of university performance appraisal system is shown in Table 2 .

ISSN: 0010-8189 
Table 2 System implementation environment table

\begin{tabular}{|c|c|c|}
\hline \multicolumn{3}{|c|}{ Software environment } \\
\hline \multirow[b]{2}{*}{ Client } & Operating system & Windows 7 \\
\hline & Development tool & $\begin{array}{c}\text { Visual Studio } 2012 \\
\text { Silverlight } \\
\text { C\# }\end{array}$ \\
\hline \multirow{2}{*}{ Server } & Operating system & Windows 7 \\
\hline & Database & Sql Server 2008 \\
\hline \multicolumn{3}{|c|}{ Hardware environment } \\
\hline Client & \multicolumn{2}{|r|}{$\begin{array}{l}\text { CPU: Intel Core i5 } \\
\text { Memory: 4GB } \\
\text { Hard disk: } 500 \mathrm{G}\end{array}$} \\
\hline \multirow{2}{*}{ Server } & Application server & CPU: ES-2603, Memory: 8GB, Hard disk: 1T \\
\hline & Database server & CPU: ES-2603, Memory: 8GB, Hard disk: $1 \mathrm{~T}$ \\
\hline
\end{tabular}

\subsection{System main interface}

The main interface of the system is shown in Figure 4. The upper part is module navigation, and the left part is function navigation.

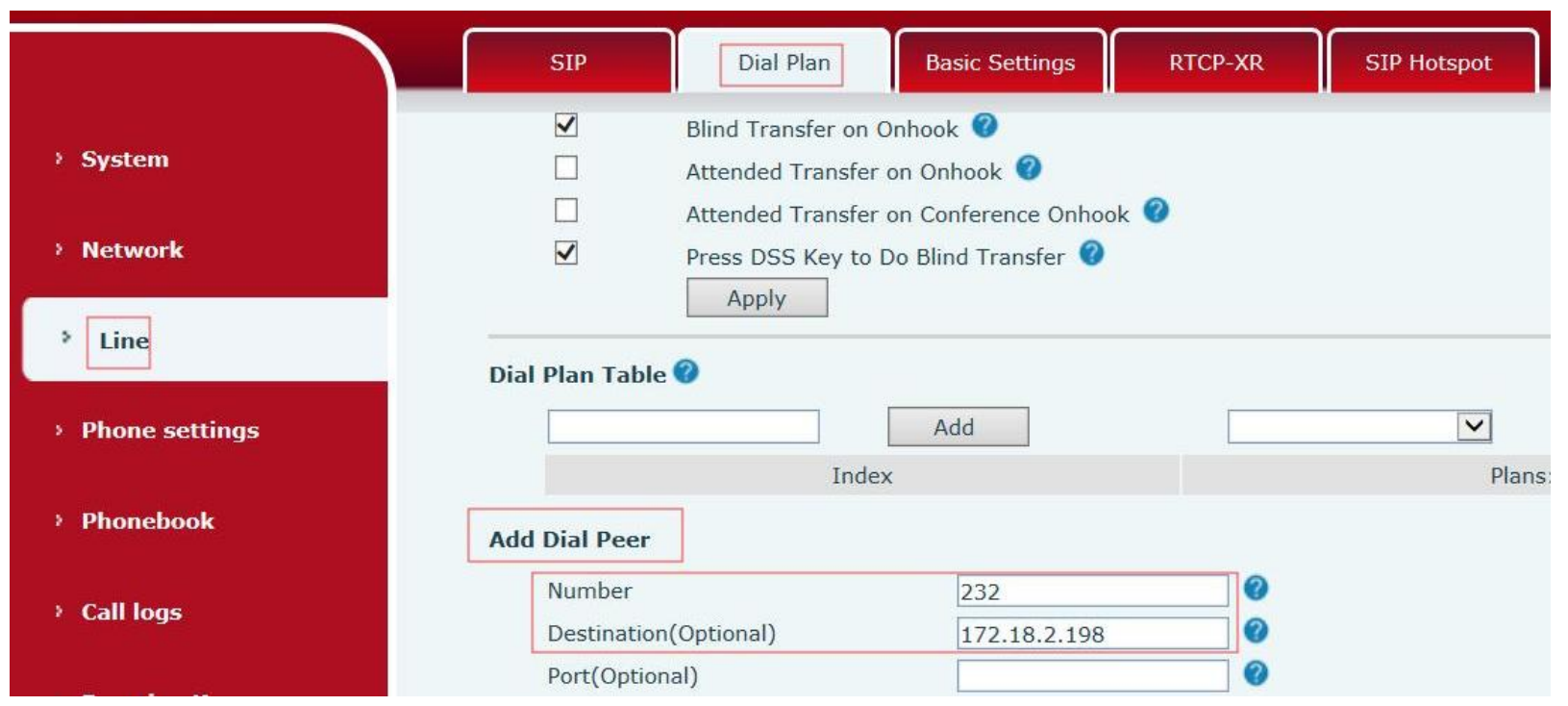

Fig 4:Main interface of performance appraisal

5.3 Assessment setting module

(1) Assessment plan management

The person in charge of personnel punishment makes an appraisal plan, and the appraisal plan list interface is shown in Figure 5. 


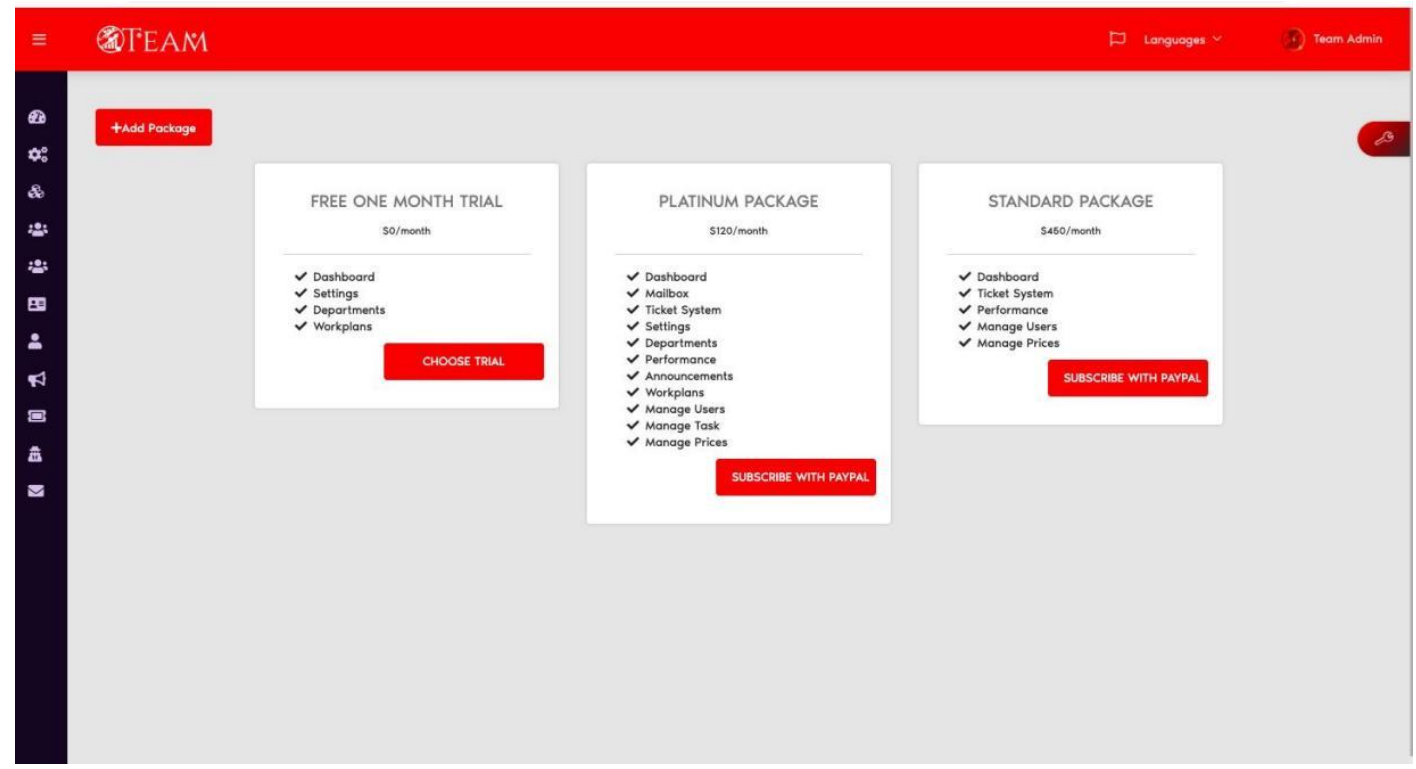

Fig 5:Appraisal plan list interface

(2) Assessment of staff allocation

Set the appraisal staff for the appraisal plan, and the interface is shown in Figure 6.

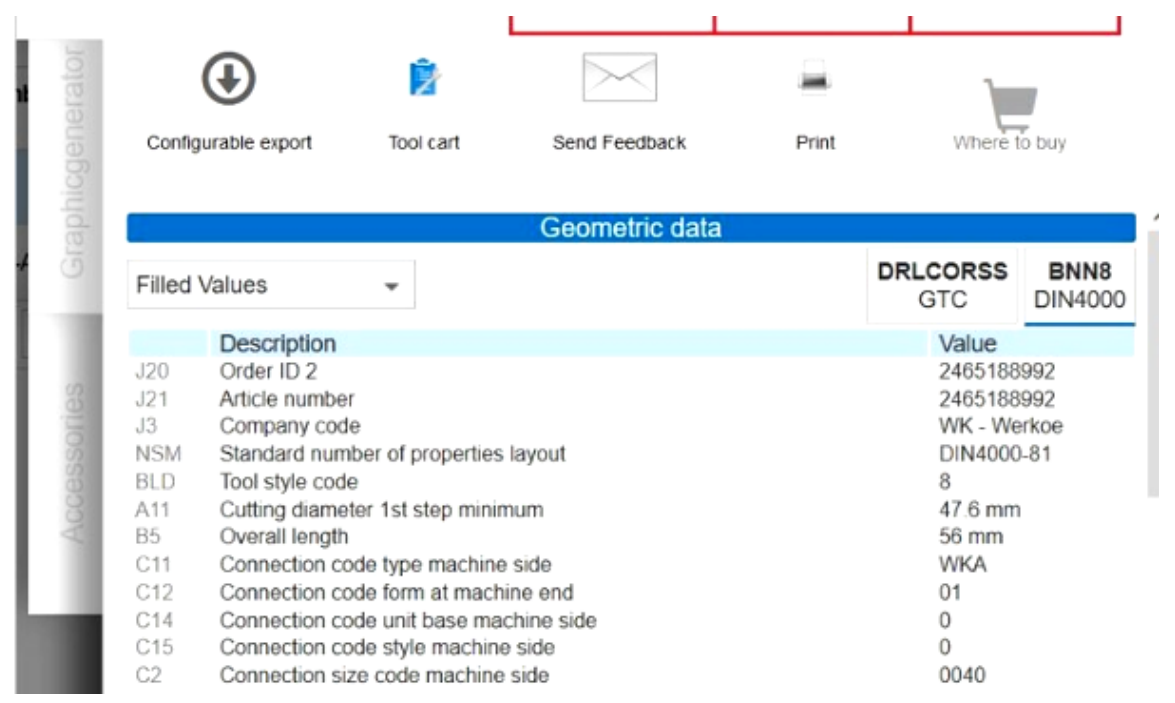

Fig 6: Evaluation plan staff configuration interface

\section{Conclusion}

In this paper, we design and develop a set of performance appraisal system for university staff, which can assist the personnel department to establish a perfect appraisal system, establish an appraisal index database in the software, and standardize the appraisal process, so as to make the appraisal process more transparent, the data source accurate and traceable. Teachers and workers can clearly understand their advantages and disadvantages in one year, and leaders can easily query, count and compare the performance of teachers and workers.

ISSN: 0010-8189 


\section{References}

[1] Lin, Y., Wang, Y., \& Kung, L. A. (2015). "Influences of cross-functional collaboration and knowledge creation on technology commercialization: evidence from high-tech industries". Industrial Marketing Management, 49, 128-138.

[2] Liu, D., \& Guo, X. (2017). "Exploring gender differences in acceptance of mobile computing devices among college students". Information Systems and e-Business Management, 11(1), 1-27.

[3] Peteet, B. J., Brown, C. M., Lige, Q. M., \& Lanaway, D. A. (2015). "Impostorism is associated with greater psychological distress and lower self-esteem for african american students". Current Psychology, 34(1), 154-163.

[4] Pinto, J. C., Loureiro, N., \& Taveira, M. D. C. (2015). "Psychological intervention in portuguese college students: effects of two career self-management seminars". Journal of College Student Development, 56(5), 518-524.

[5] Shiau, W. L., \& Chau, P. Y. K. (2016). "Understanding behavioral intention to use a cloud computing classroom: a multiple model comparison approach”. Information \& Management, 53(3), 355-365.

[6] Tzu-Fei Chen RN MSN Doctoral Student Lecturer, \& Kuei-Ru Chou PhD RN Professor. (2015). "Construct validity and reliability of the chinese version of the disaster preparedness evaluation tool in Taiwan”. Journal of Clinical Nursing, 24(7-8), 1132-1143.

[7] Wang, C. C., Chen, C. F., \& Chen, C. T. (2015). "Exploring the different aspects of internet leisure use by college students". Information Development, 31(1), 5-12.

[8] Wang, X. (2016). "Course-taking patterns of community college students beginning in stem: using data mining techniques to reveal viable stem transfer pathways". Research in Higher Education, 57(5), 544569.

[9] Zhang, Q., Goodman, M., \& Xie, S. (2015). "Integrating library instruction into the course management system for a first-year engineering class: an evidence-based study measuring the effectiveness of blended learning on students' information literacy levels". College \& Research Libraries, 76(7), 934-958.

[10] Zhou, Y. X., Ou, C. Q., Zhao, Z. T., Wan, C. S., Guo, C., \& Li, L., et al. (2015). “The impact of selfconcept and college involvement on the first-year success of medical students in china". Advances in Health Sciences Education, 20(1), 163-179. 